Goren Andy (Orcid ID: 0000-0002-8190-2289)

Kovacevic Maja (Orcid ID: 0000-0001-6579-5535)

Goldust Mohamad (Orcid ID: 0000-0002-9615-1246)

McCoy John (Orcid ID: 0000-0003-1577-9910)

\title{
LOW DOSE DAILY ASPIRIN REDUCES TOPICAL MINOXIDIL EFFICACY IN ANDROGENETIC ALOPECIA PATIENTS
}

Goren A., Sharma A., Dhurat R., Shapiro J., Sinclair R., Situm M., Kovacevic M., Skudar L V., Goldust M.,Lotti T., McCoy J.

\begin{abstract}
Topical minoxidil is the only US FDA approved OTC drug for the treatment of androgenetic alopecia (AGA). Minoxidil is a pro-drug converted into its active form, minoxidil sulfate, by the sulfotransferase enzymes in the outer root sheath of hair follicles. Previously, we demonstrated that sulfotransferase activity in hair follicles predicts response to topical minoxidil in the treatment of AGA. In the human liver, sulfotransferase activity is significantly inhibited by salicylic acid. Low dose OTC aspirin (75mg$81 \mathrm{mg}$ ), a derivative of salicylic acid, is used by millions of people daily for the prevention of coronary heart disease and cancer. It is not known whether oral aspirin inhibits sulfotransferase activity in hair follicles, potentially affecting minoxidil response in AGA patients. In this study, we determined the follicular sulfotransferase enzymatic activity following 14 days of oral aspirin administration. In our cohort of 24 subjects, 50\% were initially predicted to be responders to minoxidil. However, following 14 days of aspirin administration, only $27 \%$ of the subjects were predicted to respond to topical minoxidil. To the best of our knowledge, this is the first study to report the effect of low dose daily aspirin use on the efficacy of topical minoxidil.
\end{abstract}

Authors state no conflict of interest.

\section{INTRODUCTION}

In 1988 the US FDA approved $2 \%$ topical minoxidil solution as an OTC drug for the treatment of androgenetic alopecia (AGA). The agency found topical minoxidil to be safe and effective (US FDA, 1988). Since the FDA approval, minoxidil has become the mainstay therapy for AGA. However, the effectiveness of minoxidil in the general population is low, only $39 \%$ of patients respond to the drug (Olsen, 2007). In the pivotal study submitted to the US FDA in support of the efficacy of the $5 \%$ topical minoxidil foam, no subjects had great improvement, $8 \%$ of the subjects had a moderate improvement, and $31 \%$ of the subjects had a slight improvement (US FDA, 2009).

Minoxidil is a pro-drug converted to its active form, minoxidil sulfite, by sulfotransferase enzymes present in the outer root sheath (ORS) of hair follicles (Buhl, 1990). Recently, Goren et al. demonstrated that the activity of sulfotransferases in the ORS determines the clinical response to

This is the author manuscript accepted for publication and has undergone full peer review but has not been through the copyediting, typesetting, pagination and proofreading process, which may lead to differences between this version and the Version of Record. Please cite this article as doi: $10.1111 /$ dth.12741

This article is protected by copyright. All rights reserved. 
minoxidil (Goren, 2014). Sulfotransferase enzymes are expressed in abundance in the human liver (Riches, 2009). In the human liver, sulfotransferases are part of the Phase II enzymatic system that reduces xenobiotic toxicity (Jancova, 2010). Salicylic acid and aspirin (a derivative of salicylic acid) are well established as significant inhibitors of human liver sulfotransferases (Pacifici, 2004). Since millions of people are administered low dose $(75 \mathrm{mg}-81 \mathrm{mg})$ daily aspirin for the prevention of coronary heart disease and cancer, it is of great clinical interest to elucidate the effect of daily aspirin use on the sulfotransferase enzyme activity in the ORS. To that end, we have studied the effect of low dose daily aspirin administration on the sulfotransferase enzyme activity in the ORS of hair follicles utilizing the minoxidil response assay reported by Goren et al (Goren, 2014).

\section{METHODS}

The study was conducted at a dermatology department of a hospital (LTM Sion Medical School, Mumbai, India). Twenty-four male subjects with AGA were recruited to study (refer to Table 1). Subjects had not used topical minoxidil, oral minoxidil or aspirin during the past 6 months. Plucked hair samples were collected at the initial visit and sent for analysis utilizing the Minoxidil Response Test (Applied Biology, Inc. Irvine, California, USA). Subjects were provided 14 tablets of $75 \mathrm{mg}$ aspirin. Subjects were instructed to use one tablet per day and return to the dermatology department 14 days after initiation of therapy. Plucked hair samples were collected during the visit on the $14^{\text {th }}$ day and sent to analysis (Applied Biology, Inc. Irvine, California, USA).

\section{RESULTS}

Twenty-two of the 24 subjects returned to the dermatology department 14 days after initiation of aspirin therapy. The results of the Minoxidil Response Test were tabulated (refer to Table 1 and Graph 1) and analyzed utilizing the reported within-subject biological variability of 0.2 OD (Goren, 2018). Of the 22 subjects that completed the study, $12(55 \%)$ subjects had a significant reduction $(p<0.0001)$ in follicular sulfotransferase enzymatic activity, i.e., >0.2 OD reduction following 14 days of aspirin therapy. More importantly, the Minoxidil Response Test (MRT) initially predicted that 11 (50\%) of the 22 subjects may respond to topical minoxidil. However, following 14 days of aspirin administration only $6(27 \%)$ subjects were predicted to respond to topical minoxidil. In one of the subjects we observed an increase in sulfotransferase activity following aspirin administration. While we cannot rule-out the observed increase due to aspirin, we speculate that an extrinsic factor contributed to the increase in sulfotransferase activity.

\section{CONCLUSION}

Topical minoxidil solution is the first line of topical therapy for the treatment of androgenetic alopecia. It is available over the counter in the United States and is used by millions of men and women worldwide. While the drug has an excellent safety record, its efficacy in the treatment of AGA is limited by the sulfotransferase enzymes activity in ORS of hairs. The same enzyme is significantly inhibited in the human liver by another OTC drug used by millions of men, aspirin. In this communication, we demonstrated that low dose oral aspirin negatively inhibits the activity of sulfotransferase enzymes in the human hair ORS; therefore, chronic use of low dose aspirin is likely to interfere with the efficacy of topical minoxidil treatment. It is possible that the low efficacy observed in the studies conducted in 
support of the approval of topical minoxidil was partially due to the concomitant use of aspirin. Based on the results of this study, clinicians should take into account a patient's aspirin regimen prior to initiating minoxidil therapy for AGA.

\section{REFERENCES}

1. Buhl A.E., Waldon D.J., Baker C.A., Johnson G.A (1990). Minoxidil sulfate is the active metabolite that stimulates hair follicles. J Invest Dermatol. 95, 553-7.

2. Goren A., Castano J.A., McCoy J., Bermudez F., Lotti T. (2014). Novel enzymatic assay predicts minoxidil response in the treatment of androgenetic alopecia. Dermatol Ther. 27,171-3.

3. Goren A., McCoy J., Kovacevic M., Situm M., Chitalia J., et al. The Effect of Topical Minoxidil Treatment on Follicular Sulfotrnasferase Enzymatic Activity. Journal of Biological Regulators and Homeostatic Agents (accepted June 11, 2018)

4. Jancova P., Anzenbacher P., Anzenbacherova E. (2010). Phase II drug metabolizing enzymes. Biomed Pap Med Fac Univ Palacky Olomouc Czech Repub. 154, 103-16.

5. Olsen E.A., Whiting D., Bergfeld W., Miller J., Hordinsky M., Wanser R., et al (2007). A multicenter, randomized, placebo-controlled, double-blind clinical trial of a novel formulation of $5 \%$ minoxidil topical foam versus placebo in the treatment of androgenetic alopecia in men. $J$ Am Acad Dermatol. 57, 767-74.

6. Pacifici G.M. (2004) Inhibition of human liver and duodenum sulfotransferases by drugs and dietary chemicals: a review of the literature. Int J Clin Pharmacol Ther. 42, 488-95.

7. Riches Z., Stanley E.L., Bloomer J.C., Coughtrie M.W.H.(2009). Quantitative evaluation of the expression and activity of five major sulfotransferases (SULTs) in human tissues: the SULT "pie". Drug Metab Dispos. 37, 2255-61.

8. US FDA New Drug Application (NDA) 019501

9. US FDA Application 21-812 Medical Review. 


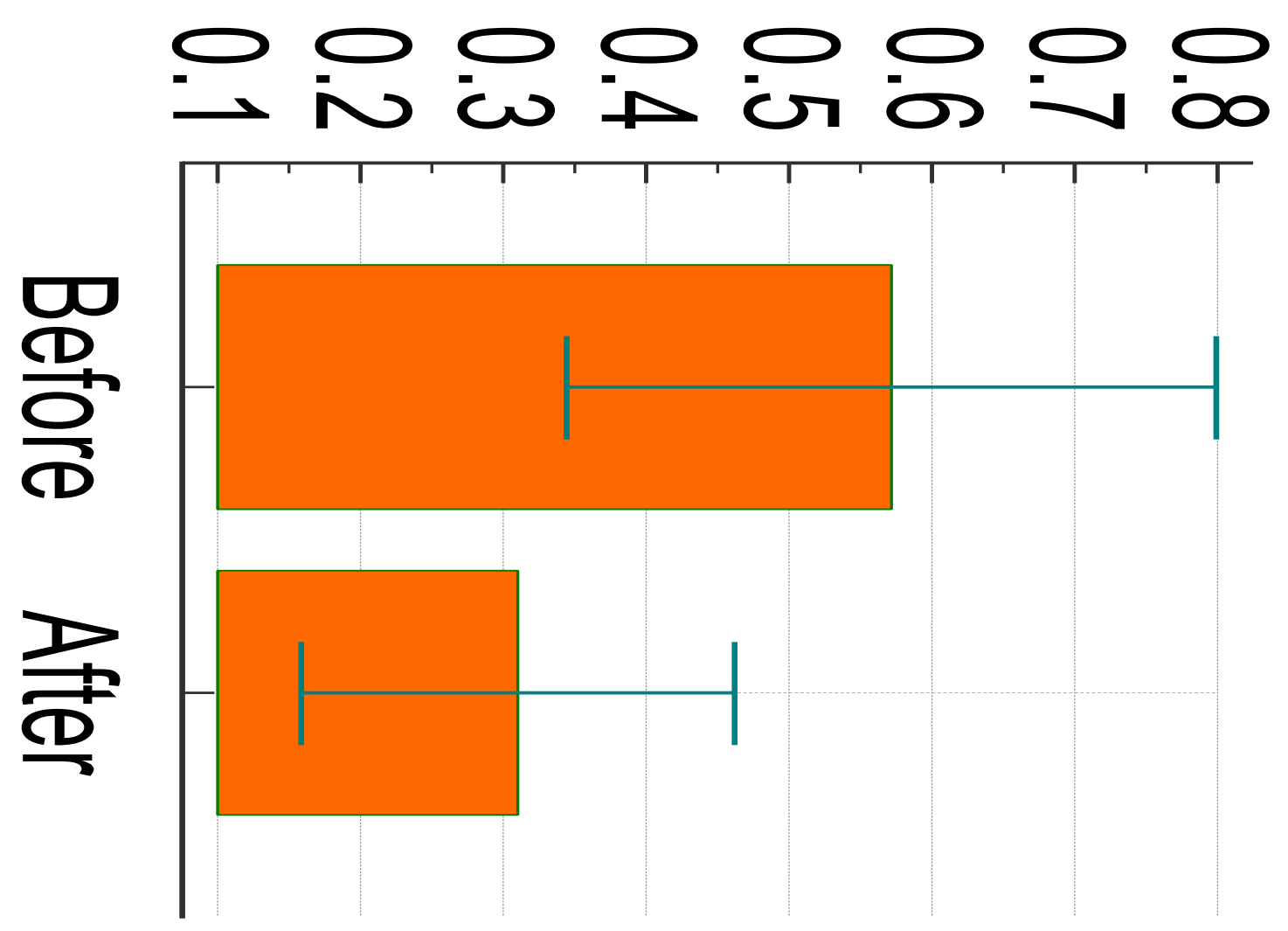

Graph 1. The sulfotransferase enzymatic activity of the subjects before and after 14 days of low dose $(75 \mathrm{mg})$ daily aspirin regimen. 


\begin{tabular}{|c|c|c|c|c|c|}
\hline Subject & Sex & Age & $\begin{array}{c}\text { Before } \\
\text { (OD) }\end{array}$ & After (OD) & Delta (OD) \\
\hline 1 & $\mathrm{M}$ & 33 & 1.121 & 0.304 & 0.817 \\
\hline 2 & $\mathrm{M}$ & 25 & 0.7648 & 0.2124 & 0.5524 \\
\hline 3 & $\mathrm{M}$ & 40 & 0.6550 & 0.2500 & 0.4050 \\
\hline 4 & $\mathrm{M}$ & 30 & 1.4920 & 0.5000 & 0.9920 \\
\hline 5 & $\mathrm{M}$ & 30 & 0.1792 & 0.0540 & 0.1252 \\
\hline 6 & $\mathrm{M}$ & 28 & 0.0168 & 0.0132 & 0.0036 \\
\hline 7 & $\mathrm{M}$ & 33 & 0.4040 & 0.084 & 0.3200 \\
\hline 8 & $\mathrm{M}$ & 29 & 0.3492 & 0.1999 & 0.1493 \\
\hline 9 & $\mathrm{M}$ & 28 & 0.0500 & 0.1034 & -0.0534 \\
\hline 10 & $\mathrm{M}$ & 28 & 0.0416 & 0.2176 & -0.1760 \\
\hline 11 & $\mathrm{M}$ & 24 & 0.3656 & 0.0368 & 0.3288 \\
\hline 12 & $\mathrm{M}$ & 25 & 0.1130 & 0.0590 & 0.0540 \\
\hline 13 & $\mathrm{M}$ & 28 & 0.1470 & 0.2170 & -0.0700 \\
\hline 14 & $\mathrm{M}$ & 29 & 0.5448 & 0.2648 & 0.2800 \\
\hline 15 & $\mathrm{M}$ & 19 & 0.887 & 0.096 & 0.791 \\
\hline 16 & $\mathrm{M}$ & 30 & 0.6408 & 0.249 & 0.3918 \\
\hline 17 & $\mathrm{M}$ & 28 & 0.1808 & 0.2488 & -0.0680 \\
\hline 18 & $\mathrm{M}$ & 27 & 0.9528 & 0.5608 & 0.3920 \\
\hline 19 & $\mathrm{M}$ & 24 & 1.5432 & 0.5248 & 1.0184 \\
\hline 20 & $\mathrm{M}$ & 20 & 1.6648 & 1.6368 & 0.0280 \\
\hline 21 & $\mathrm{M}$ & 36 & 0.1024 & 0.4784 & -0.3760 \\
\hline 22 & $\mathrm{M}$ & 30 & 0.3620 & 0.512 & -0.1500 \\
\hline
\end{tabular}

Table 1. The sulfotransferase enzymatic activity of the subjects before and after 14 days of low dose $(75 \mathrm{mg})$ daily aspirin regimen.

This article is protected by copyright. All rights reserved. 


\section{University Library}

\section{- M M N E R VA A gateway to Melbourne's research publications}

Minerva Access is the Institutional Repository of The University of Melbourne

\section{Author/s:}

Goren, A;Sharma, A;Dhurat, R;Shapiro, J;Sinclair, R;Situm, M;Kovacevic, M;Skudar, VL;Goldust, M;Lotti, T;McCoy, J

Title:

Low-dose daily aspirin reduces topical minoxidil efficacy in androgenetic alopecia patients

\section{Date:}

2018-11-01

\section{Citation:}

Goren, A., Sharma, A., Dhurat, R., Shapiro, J., Sinclair, R., Situm, M., Kovacevic, M., Skudar, V. L., Goldust, M., Lotti, T. \& McCoy, J. (2018). Low-dose daily aspirin reduces topical minoxidil efficacy in androgenetic alopecia patients. DERMATOLOGIC THERAPY, 31 (6), https://doi.org/10.1111/dth.12741.

Persistent Link:

http://hdl.handle.net/11343/284613 